\title{
The Contribution of the Global Framework for Climate Services Adaptation Programme in Africa (GFCS APA) in National Adaptation Plan (NAP) Process for Tanzania
}

\author{
Philbert Luhunga ${ }^{*}$, Emanuel T. Kidebwana ${ }^{2}$, Agnes Kijazi ${ }^{1}$, Ladislaus Chang'a1, \\ Hashim Ng'ongolo ${ }^{3}$ Mecklina Merchades ${ }^{4}$, Pamela Levira1 \\ ${ }^{1}$ Research Section, Tanzania Meteorological Authority, Dar es Salaam, Tanzania \\ ${ }^{2}$ Information and Communication Technology (ICT) Section, Tanzania Meteorological Authority, Dar es Salaam, Tanzania \\ ${ }^{3}$ Climatology and Climate Change Section, Tanzania Meteorological Authority, Dar es Salaam, Tanzania \\ ${ }^{4}$ Agrometeorological Section, Tanzania Meteorological Authority, Dar es Salaam, Tanzania \\ Email: *philuhunga@yahoo.com
}

How to cite this paper: Luhunga, P., Kidebwana, E.T., Kijazi, A., Chang'a, L., Ng'ongolo, H., Merchades, M. and Levira, P. (2019) The Contribution of the Global Framework for Climate Services Adaptation Programme in Africa (GFCS APA) in National Adaptation Plan (NAP) Process for Tanzania. Atmospheric and Climate Sciences, 9, 650-661.

https://doi.org/10.4236/acs.2019.94040

Received: August 23, 2019

Accepted: October 21, 2019

Published: October 24, 2019

Copyright $\odot 2019$ by author(s) and Scientific Research Publishing Inc. This work is licensed under the Creative Commons Attribution International License (CC BY 4.0).

http://creativecommons.org/licenses/by/4.0/ (c) (i) Open Access

\begin{abstract}
This article assesses the contribution of the Global Framework for Climate Services Adaptation Programme in Africa (GFCS APA) in the National Adaptation Plan (NAP) process for Tanzania. Different research project outputs (field survey and workshop reports) produced during the implementation of GFCS APA are reviewed to assess the contribution of GFCS APA programme in the establishment and implementation of NAP process in Tanzania. It is found that the implementation of GFCS-APA programme in Tanzania has improved the availability, accessibility, and applicability of climate information to different stakeholders. This has in turn attributed to significant use of climate information in planning and decision making in target sectors: agriculture and food security, disaster risk reduction, energy, health and water resource management. This has increased the adaptation capacity of vulnerable communities from the impacts of climate variability and change. Furthermore, it is evident that the aims and objectives of establishments of NAP process in Tanzania have been addressed through implementation of GFCS APA Programme. Moreover, since the GFCS APA in Tanzania is implemented within its five pillars namely: observation and monitoring, research, modeling and prediction, climate information systems, user interface platform and capacity development. The achievement made in each pillar contributed in enhancement of resilience of vulnerable communities to climate variability and change hence addressing the aims and objectives of NAP process in Tanzania. Therefore, it is recommended that achievements of
\end{abstract}


GFCS APA Programme in Tanzania to be used as a guide to the development and implementations of the NAP process in Tanzania.

\section{Keywords}

Global Framework for Climate Services, World Meteorological Organization, National Adaptation Plan

\section{Introduction}

Climate change is unequivocal, it is coming to us faster with lager impacts and bigger risks than even most climate scientists expected as recently as a few years ago [1] [2]. Its impacts are predicted to present significant challenges to efforts of achieving sustainable development goals in many countries around the world, particularly in developing countries [3]. In order to reduce the impacts of climate change countries around the world are required to start taking necessary steps in developing adaptation strategies and plans that can be mainstreamed into development projects. This is urgently required especially in Developing Countries (DCs) and Least Developed Countries (LDCs) that are more vulnerable to the impacts of climate change.

The high vulnerabilities of DCs and LDCs to impacts of climate change is attributed to their high dependence on sectors that are sensitive to climate change and low adaptative capacity to the impacts of climate change. This was recognized by the Conference of Parties (COP) to the United National Framework Convention on Climate Change (UNFCCC) in 2010 and contributed to the establishment of the National Adaptation Plan (NAP) process.

The NAP process was established as the way to facilitate effective adaptation planning in LDCs and other developing countries with the aims of: 1) enhancement of country led planning and preparedness for Climate Change Adaptation (CCA) in the medium and long term, 2) reduce vulnerability to the impacts of climate change and 3) integrate adaptation into all levels of development planning process [4].

The objectives of the NAP process identified by COP includes: 1) To reduce vulnerability to the impacts of climate change, by building adaptive capacity and resilience and 2) To facilitate the integration of climate change adaptation, in a coherent manner, into relevant new and existing policies, programmes and activities, in particular development planning processes and strategies, within all relevant sectors and at different levels, as appropriate [5].

The COP suggested that NAP process should be a continuous, progressive and iterative process and its implementation could be measured from country identified priorities, including those in the relevant national documents, plans and strategies, and coordinated with national sustainable development objectives, plans, policies and programmes [5]. More over the COP acknowledged that for enhanced action on adaptation, NAP process should be: 1) a country driven ef- 
fort, gender sensitive, developed under participatory approach, full transparent, taking into account vulnerable communities and ecosystems 2) informed and guided by the best available science, appropriate traditional and indigenous knowledge, gender sensitive approaches with the focus of integrating adaptation into all relevant socioeconomic and environmental policies and action where appropriate 3) not be prescriptive, nor results in duplication of efforts undertaken in a country but rather facilitate country-owned, country-driven action.

The establishment of NAP process could be understood when the term adaptation is properly defined. The [5] defined adaptation as a human-driven adjustment in ecological, social or economic systems or policy processes in response to actual or expected climate stimuli and their impacts or effects. This is achieved through implementing new activities that are exclusively in response to climate change or adjust existing activities to make them more resilient to current and future climate change risks. The designing of adaptation therefore varies case by case depending to the complex nature of adaptation. It is therefore very important to involve a broad range of stakeholders in the process of effective planning and implementation of NAP process. This paper evaluates the contribution of the Global Framework for Climate Services Adaptation Programme in Africa (GFCS APA) in NAP process for Tanzania.

\section{The Global Framework for Climate Services Adaptation Programme in Africa (GFCS APA)}

The Global Framework for Climate Services Adaptation Programme in Africa (GFCS APA) is a multi-agency joined effort programme that is implemented under the umbrella of the Global Framework for Climate Services (GFCS) and funded by the government of Norway through the ministry of foreign affairs. The main objective of the programme is enhancing the resilience of the most vulnerable communities to the adverse impacts of climate variability and change, through promoting the use of climate services at all levels particularly in the priority areas of agriculture and food security, disaster risk reduction, energy, health and water resource management [6] [7].

In Africa the GFCS APA is implemented in Tanzania and Malawi whereby, phase 1 of the programme was implemented from 2014 to 2016 and Phase II of the programme started in 2016 and will close in 2019. In order to ensure effective implementation, the GFCS APA is structured to run under five key pillars (Figure 1), namely: observation and monitoring, Research Modeling and Prediction, Climate Information System, and User Interface Platform which are all supplemented with Capacity Development.

The Observation and Monitoring pillar focuses mainly on enhancement of the distribution of meteorological observations at spatial and temporal scales. The pillar hence highlights the needs of having infrastructures to collect and manage climate data necessary for provision of quality climate services [9]. Under this pillar the National Meteorological and Hydrological Services (NMHS) are responsible for compilation and provision of climate information to users. However, 


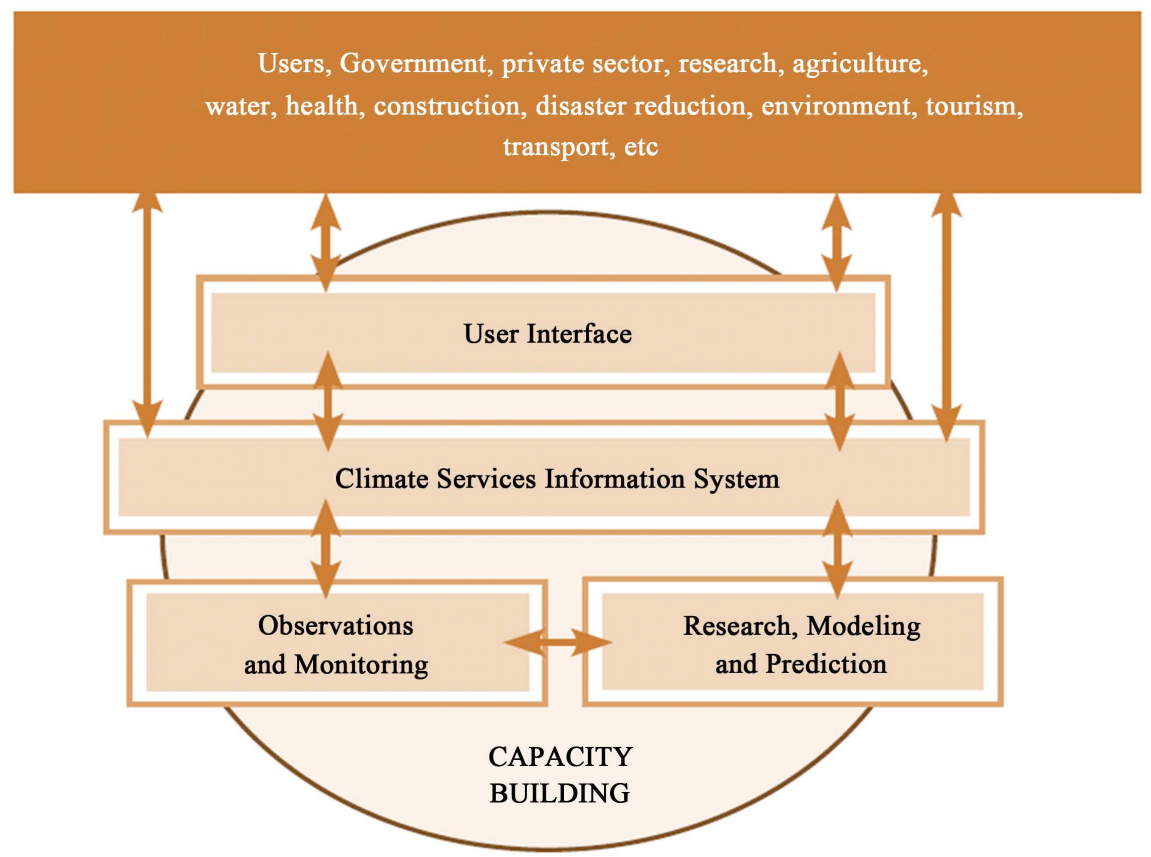

Figure 1. The pillars of the GFCS APA programme (adopted from [8]).

before the provision of climate information to users, the NMHS needs to ensure adequate quality climate observation for diverse applications such as managing and monitoring climate related risks. In general, quality and adequate climate information are important for analyses and understanding of the past climate, monitoring of the present climate and for the projection of future climate. This information is essential and can be used by different stakeholders for adaptation of climate variability and change.

The User Interface Platform (UIP) is aiming at enabling users of climate services, climate researchers and climate services providers to interact at the global, regional and national levels to maximizing access and utilization of climate services [10] [11]. The UIP provides optimal methods for obtaining feedbacks from user of climate services. Moreover, it provides dialogues between users of climate services and those responsible in other pillars such as observation and monitoring, research, modeling and prediction and climate services information system [12]. UIP enhances the climate literacy in the user community, and literacy of the climate community in the user needs. Successfully implemented UIP build a strong relationship between users of climate services and climate service providers that lead to enhancement effectiveness in the use of climate services thus significantly contribute to climate informed adaptation planning and decision-making.

The Climate Services Information System (CSIS) pillar focuses on determining effective mechanisms on how climate information (historical, current and future) are routinely collected, stored and analyzed to generate climate products that inform planning and decision making across a wide range of climate sensitive sectors. Moreover, the CSIS provides mechanisms to access and distribute climate information and products according to the rules, restrictions, standards, 
and procedures prescribed by climate producers [10] [11].

The research, modeling and prediction pillar is structured to assess and promote the needs of climate services within research, modeling and climate prediction agendas. The pillar focuses on the improvement of quality of climate information and provides scientific evidence on the impacts of climate variability and change. Moreover, the pillar provides the cost benefit analysis of using climate information in planning and decision making. It involves interdisciplinary research fields focusing on assessment of the socio-economic impacts of climate change and provides adaptation options for existing and anticipated climate change pathways scenarios.

The capacity development pillar cuts cross into all other pillars of the framework. It intends to provides developmental needs in other pillars and more generally to support the basic requirements to enable different activities within the framework to occur and support systematic development of the institutions, infrastructure and human resources required for effective delivery of climate services

\section{The Implementation of GFCS APA Programme in Tanzania}

The GFCS APA Programme in Tanzania is implemented over Longindo and Kiteto districts located in the northeastern part of Tanzania and Kondoa district located in the central part of Tanzania. These areas were selected based on the existing climate change adaptation initiatives. The programme is implemented in two phases, where the first phase started from 2014 and closed in 2016 and the second phase started from 2016 and will close in 2019.

The first phase of the programme was implemented by multi agency partners namely: The Tanzania Meteorological Authority (TMA), Ministry of Agriculture (MoA), Ministry of Health, Community Development, Gender, Elderly and Children (MoHCDGEC), the University of Dar es Salaam, CGIAR Research Programme on Climate Change, Agriculture and Food Security (CCAF), Tanzania Red Cross (TRC), the World Food Programme (WFP-Tanzania), and the World Health Organization (WHO-Tanzania). While the second phase of the project is implemented by all project partners mentioned above with exception of CCAF and the University of Dar es Salaam.

The project partners implemented several activities under each of the five pillars of GFCS APA in priority sectors namely: agriculture and food security, disaster risk reduction and nutrition and health sectors. The implementation strategy of GFCS APA in Tanzania started with the identification of key committees. The first committee is the Programme Steering Committee (PSC). This committee is comprised with representatives from each implementation partner and is responsible for management of all project activities. The PSC conducts meetings biannually and are chaired by representative from the WMO. The second committee is the National Steering Committee (NSC), which is mandated to oversee the implementation of the programme at national level and development of the National Framework for Climate Services. The third committee is the Project Delivery Team (PDT). This responsible for planning and implementation of 
joint activism as well as monitoring progress of the programme activities. The PDT meets on quarterly basis and is chaired by representative from the Tanzania Meteorological Authority.

\section{The Achievements of GFCS APA Programme in Tanzania}

The GFCS APA programme in Tanzania aimed to strengthen the climate resilience of the most vulnerable communities to the adverse impacts of climate variability and change, through promoting the use of climate services at all levels in the project priority areas of agriculture and food security, disaster risk reduction, energy, health and water resource management. The achievements of GFCS APA in Tanzania are summarized as follows:

1) Improved capacity of implementation partners in production, disseminations and use of climate information

Through the implementation of GFCS APA in Tanzania, the capacity of project implementation partners in production, disseminations and use of climate information have increased. For instance, capacity of TMA in production of tailor-made products such as downscaled seasonal outlooks, and climate data management have increased. Moreover, the capacity of TMA in provision of specialized forecast such marine forecast, general weather forecast and climate prediction together with interpretation of developed climate products has increased.

Capacity is also built to intermediaries (extension workers, media, and Red Cross volunteers) to enhance knowledge of climate services provided by TMA for effective dissemination. In addition, the programme has procured various tools including twelve computers, two printers, a tape recorder, a laptop, a projector, and GIS software. These tools have enhanced production and provision of quality climate services to users.

2) Enhanced awareness and accessibility of climate services

Programme seminars, workshop, household visits, and dialogues have enhanced awareness among users of climate services. The visit and seminars reached about 4000 stakeholders to support the application of climate information in various socio-economic planning and decision-making. During seminars and workshops, stakeholders registered to receive climate information through mobile phones (FarmSMS). About 3600 users registered in the system.

\section{3) Provision of downscaled seasonal forecast}

Provisión of downscaled forecast at district level has improved the usefulness of climate information to local communities. The downscaled forecasts provided details of the expected climatic conditions to support informed decisions such as what and when to plant. The downscalled forecast was produced in Kiteto, Longido and Kondoa districts.

\section{4) Rehabilitation of earthdam}

The earth dam in Olpopong village, Kiteto district has been rehabilitated to enhance its capacity to conserve water. The rehabilitation involved planting of 
trees, construction of water reservoirs, and procurement of new gate valve for controlling water flows. The gate valves are also used to connect the earth dam reservoir and the cattle trough. The programme acquired trees from the community tree nursery and planted around the dam.

\section{5) Enhanced Institutional colaboración}

The collaboration between various institutions enhanced effective dissemination of climate services among stakeholders which supported mainstreaming of climate information in various institutions. An example is the collaboration enhanced during GFCS implentation between TMA and Ministry of Agriculture through FarmSMS. This has played a significant role in enhancing availability, accessibility, and applicability of climate information in Agriculture and Food security. The collaboration is the stepping stone towards enhancing and sustaining improved climate services.

\section{6) Development of the National Framework for Climate Services}

In order to sustain the GFCS initiatives, the National Framework for Climate Services (NFCS) has been developed. The Framework aims to enhance the provisional of climate services and promote its use for risk reduction caused by the impacts of climate variability and change. The NFCS bring together all actors in climate services to engage in the provision, dissemination, and application of climate information, in development plans and decision making. This ensures resilience to climate-related disasters through the development of adaptation strategies.

The GFCS achievement can be analysed per sector. For instance, in the Agriculture and Food Security: GFCS implementation facilitated adaption to climate shocks through

a) Timely provision, access to weather and climate information to reduce climate impacts through timely preparedness and planning.

b) Capacity development to extension workers for informed decisions.

c) Climate change awareness to internally displaced people so they take appropriate actions.

d) Enhanced dissemination of weather information for seasonal planning and adjustment for risks reduction.

e) Awareness raising to pastoralist communities on the importance of climate services to environmental conservation and sustainable livestock management.

In the Nutrition and Health Sector: the GFCS programme helped the health sector in the following aspects:

a) Strengthened communication and partnerships among climate and health actors at all levels.

b) Increased capacity of the health sector to effectively access, understand and use climate and weather information for health decisions.

c) Improved health and climate research and evidence of the linkage of climate and health.

d) Climate and weather data effectively mainstreamed into health operations. 


\section{Contribution of GFCS APA in NAP Process for Tanzania}

The main aim of establishment of the NAP process are: enhancement of country led planning and preparedness for Climate Change Adaptation (CCA) in the medium and long term, thereafter reduce vulnerability of communities to the impacts of climate change and integrate adaptation strategies into all levels of development planning process [4]. While the objectives of establishments of NAP process are: 1) To reduce vulnerability to the impacts of climate change, by building adaptive capacity and resilience and 2) To facilitate the integration of climate change adaptation, in a coherent manner, into relevant new and existing policies, programmes and activities, in particular development planning processes and strategies, within all relevant sectors and at different levels, as appropriate. These aims and objectives of NAP process have been addressed through implementation of GFCS APA programme in Tanzania. For instance, the implementation of GFCS APA in Tanzania has contributed to increased development of user driven climate services from the target sectors: agriculture and food security, disaster risk reduction, energy, health and water resource management. Moreover, since the GFCS APA in Tanzania is implemented within its five pillars namely: observation and monitoring, research, modeling and prediction, climate information systems, user interface platform and capacity development. The achievement made in each pillar contributed in enhancement of resilience of vulnerable communities to climate variability and change hence addressing the aims and objectives of NAP process in Tanzania.

One of the suggestions recommended by COP in regard to have enhanced action on adaptation, the establishment of NAP process should engage a wide range of stakeholders and developed under participatory approach. This is considered during implementation of GFCS APA in Tanzania where there is high involvement of relevant stakeholders including the Vice President's Office, division of Environment. These are mandated to coordinate the preparation and implementation of the NAP process in Tanzania. Therefore the lesson learned during implementation of GFCS APA in Tanzania will help the country coordinator of the NAP process and other relevant stakeholders to smooth development and implementation of NAP process in Tanzania.

The institutional arrangements and capacity development established under the implementation of the GFCS APA in Tanzania could be used in the establishment and implementation of NAP process in Tanzania. For instance, during implementation of GFCS APA the Project Delivery Team (PDT) was established. This team among other tasks is responsible for overseeing the day to day implementation of the GFCS APA activities in Tanzania. This team could be used for provision of technical guidance in the preparation of NAP process.

During the implementation of GFCS APA programme in Tanzania different research outputs and reports were produced. For example, the Tanzania Health National Adaptation Plan (HNAP) and the National Framework for Climate Services were developed [13] [14]. These documents are important for successful implementation of NAP process in Tanzania. Table 1 below summarizes some 
Table 1. The contribution of GFCS in NAP preparation process.

\begin{tabular}{|c|c|c|}
\hline Element & Steps & Climate services and products \\
\hline \multirow[t]{3}{*}{$\begin{array}{l}\text { Laying the } \\
\text { groundwork } \\
\text { and addressing } \\
\text { the gaps }\end{array}$} & $\begin{array}{l}\text { Stocktaking: identifying } \\
\text { available information on } \\
\text { climate change impacts, } \\
\text { vulnerability and adaptation } \\
\text { and assessing gaps and needs } \\
\text { of the enabling environment } \\
\quad \text { for the NAP process }\end{array}$ & $\begin{array}{l}\text { Meteorological data on temperature and rainfall have been scanned, digitized, } \\
\text { and stored into CLIDATA and ELO database system for } 263 \text { meteorological stations } \\
\text { from Njombe, Iringa, Mbeya and Ruvuma. In addition, data gaps has been identified } \\
\text { for daily rainfall, maximum and minimum temperature data from the digitized } \\
\text { data in CLIDATA. The digitization of meteorological data has enhanced } \\
\text { data accessibility from the archive through the developed inventory and } \\
\text { effective and efficient delivery of better climate services. } \\
\text { The digitized data will enhance the quality and quantity of the historical climate } \\
\text { data for adaptation by providing valuable additional data for a variety of applications, } \\
\text { including monitoring of climate change, issuing advisories and providing } \\
\text { meteorological services much more efficiently and effectively. } \\
\text { Baseline survey was conducted in Longido, Kiteto and Kondoa to ensure smooth } \\
\text { implementation of the project activities, including scoping stakeholders' needs. } \\
\text { Further a number of researches/studies were conducted. The studies include } \\
\text { climate change analysis and inventory in Tanzania, institutional Analysis and Baseline } \\
\text { for monitoring and evaluating user satisfaction with climate services in Tanzania. } \\
\text { Other research studies focusing on climate change adaptation were conducted } \\
\text { by } 12 \text { Dar es salaam University students } \\
\text { National stakeholder's consultation workshop and seminars were conducted } \\
\text { aiming at identifying the institutional and operational needs, gaps, and } \\
\text { capacities of climate services in the Agriculture, Food security, Health, } \\
\text { and Disaster Risk Reduction sectors in Tanzania. }\end{array}$ \\
\hline & $\begin{array}{l}\text { Addressing capacity gaps and } \\
\text { weaknesses in undertaking } \\
\text { the NAP process }\end{array}$ & $\begin{array}{l}\text { The needs and gaps identified on GFCS survey, studies, workshop and seminars } \\
\text { contributes on the gaps, which needs to be addressed during NAP } \\
\text { stocktaking exercise. Addressing the identifying needs and gaps } \\
\text { will facilitate the effective implementation of NAP }\end{array}$ \\
\hline & $\begin{array}{l}\text { Comprehensively and iteratively } \\
\text { assessing development needs } \\
\text { and climate vulnerabilities }\end{array}$ & $\begin{array}{l}\text { The GFCS programme report provided information to NAP team on risk-assessment } \\
\text { demand and requirements and incorporate relevant climate observations, statistical } \\
\text { analysis, forecasts and projections of the weather, hydrological and climate-related } \\
\text { extremes in risk assessment processes } \\
\text { The reviewed meteorological information in the NAP report is important to } \\
\text { lay out the baseline information to facilitate benchmark for adaptation planning. }\end{array}$ \\
\hline \multirow{3}{*}{$\begin{array}{l}\text { Preparatory } \\
\text { elements }\end{array}$} & $\begin{array}{l}\text { Analyzing current climate and } \\
\text { future climate change scenarios }\end{array}$ & $\begin{array}{l}\text { - The GFCS program will provide forecasts and trend analysis of hazard } \\
\text { characteristics at different temporal and spatial resolutions } \\
\text { - The program with as well provide risk analysis } \\
\text { (multi-hazard, multi-level and multi-sector) } \\
\text { - The program will provide information requirements as required }\end{array}$ \\
\hline & $\begin{array}{l}\text { Assessing climate vulnerabilities } \\
\text { and identifying adaptation options } \\
\text { at sector, subnational, national } \\
\text { and other appropriate levels }\end{array}$ & $\begin{array}{l}\text { GFCS products can be used to define requirements for climate services and other } \\
\text { non-climate inputs for planning investment in reducing climate vulnerabilities } \\
\text { - Engage stakeholders for implementation - finance and planning ministries, disaster } \\
\text { risk management authorities, local authorities and government, private sector, etc. } \\
\text { - Establish coordination and information channels for relevant inputs }\end{array}$ \\
\hline & $\begin{array}{l}\text { Reviewing and appraising } \\
\text { adaptation option }\end{array}$ & $\begin{array}{l}\text { GFCS products contributed to identify stakeholders and existing processes } \\
\text { for hazard loss-accounting system implementation } \\
\text { - Identify information channels } \\
\text { - Coordinate development of relevant climate products and services in relation } \\
\text { to specific application to decision-making in different sectors }\end{array}$ \\
\hline \multirow{2}{*}{$\begin{array}{l}\text { Implementation } \\
\text { strategies }\end{array}$} & $\begin{array}{l}\text { Prioritizing climate change } \\
\text { adaptation in national planning }\end{array}$ & $\begin{array}{l}\text { GFCS products contributed to identify priority regions based on analysis of } \\
\text { vulnerability to weather and climate extremes and other important } \\
\text { factors and future projections }\end{array}$ \\
\hline & $\begin{array}{l}\text { Developing a (longterm) } \\
\text { national adaptation } \\
\text { Implementation strategy }\end{array}$ & $\begin{array}{l}\text { GFCS products contributed to identifying the areas where current information on } \\
\text { weather and climate is inadequate } \\
\text { - Strengthen the meteorological observation networks, data analysis and applications }\end{array}$ \\
\hline
\end{tabular}




\begin{tabular}{|c|c|c|}
\hline & $\begin{array}{c}\text { Enhancing capacity for } \\
\text { planning and implementation } \\
\text { of adaptation }\end{array}$ & $\begin{array}{l}\text { GFCS products contributed to strengthen operational climate services, } \\
\text { including analysis, forecasts and projection of climatic regimes and } \\
\text { probabilities and scenarios related to extreme patterns } \\
\text { - Promote interoperability of health, socioeconomic and biological data with weather, } \\
\text { hydrological and climate extremes and changes in their characteristics }\end{array}$ \\
\hline & $\begin{array}{l}\text { Promoting coordination and } \\
\text { synergy at the regional level } \\
\text { and with other multilateral } \\
\text { environmental agreements }\end{array}$ & $\begin{array}{l}\text { Linking climate strategies from global, regional, to national levels } \\
\text { in collaboration with WMO Regional Climate Centers }\end{array}$ \\
\hline \multirow{3}{*}{$\begin{array}{l}\text { Reporting, } \\
\text { monitoring } \\
\text { and review }\end{array}$} & Reporting & $\begin{array}{l}\text { GFCS products contributed to provide baseline information for reporting on } \\
\text { which progress is measured/changes in adaptation effort is measured. }\end{array}$ \\
\hline & Monitoring & The climate information will be used to monitor the adaptation process \\
\hline & Review & $\begin{array}{l}\text { The GFCS programme will provide the information for the review of NAP } \\
\text { in terms of effectiveness and efficiency of NAP program }\end{array}$ \\
\hline
\end{tabular}

of the GFCS outputs that are essential in supporting the NAP process in Tanzania.

\section{Conclusions and Recommendation}

The main aim of this paper was to evaluate the contribution of the Global Framework for Climate Services Adaptation Programme in Africa (GFCS APA) in National Adaptation Plan (NAP) process for Tanzania. It is found that the aims and objectives of establishments of NAP process in Tanzania have been addressed through implementation of GFCS APA programme. For instance, the implementation of GFCS APA activities have contributed to increased development of user driven climate services from the target sectors: agriculture and food security, disaster risk reduction, energy, health and water resource management. Moreover, since the GFCS APA in Tanzania is implemented within its five pillars namely: observation and monitoring, research, modeling and prediction, climate information systems, user interface platform and capacity development. The achievement made in each pillar contributed in enhancement of resilience of vulnerable communities to climate variability and change hence addressing the aims and objectives of NAP process in Tanzania.

The institutional arrangements and capacity development established under the implementation of the GFCS APA in Tanzania could be used in the establishment and implementation of NAP process in Tanzania. Moreover, during the implementation of GFCS APA programme in Tanzania different research outputs and reports were produced. Such documents include the Tanzania Health National Adaptation Plan (HNAP) and the National Framework for Climate Services. These documents are important for the successful implementation of NAP process in Tanzania. It is therefore recommended that achievements of GFCS APA programme in Tanzania are used to guide the development and implantations of the NAP process in Tanzania. 


\section{Acknowledgements}

The authors acknowledge funding support from the Global Framework for Climate Service (GFCS) phase II through the World Meteorological Organization (WMO). Special thanks go to colleagues from the Tanzania Meteorological Agency (TMA) for fruitful discussion and recommendations that helped to improve this article.

\section{Conflicts of Interest}

The authors declare no conflicts of interest regarding the publication of this paper.

\section{References}

[1] IPCC (2007) Working Group II Fourth Assessment Report. Climate Change: Climate Change Impacts, Adaptation and Vulnerability. http://www.ipcc.ch/SPM6avr07.pdf

[2] Luhunga, P.M. (2017) Assessment of the Impacts of Climate Change on Maize Production in the Southern and Western Highlands Sub-Agro Ecological Zones of Tanzania. Frontiers in Environmental Science, 5, 51. https://doi.org/10.3389/fenvs.2017.00051

[3] McElroy, M. and Baker, D.J. (2012) Climate Extremes: Recent Trends with Implications for National Security. Harvard University Center for the Environment, $126 \mathrm{p}$. Ebi, K.L. and Villalobos Prats, E. (2015) Health in National Climate Change Adaptation Planning. Annals of Global Health, 81, 418-426. https://doi.org/10.1016/j.aogh.2015.07.001

[4] World Meteorological Organization (2016) Climate Services for Supporting Climate Change Adaptation, Supplement to the Technical Guidelines for The National Adaptation Plan Process, WMO-No. 1170, World Meteorological Organization (WMO) 7 bis, Switzerland. https://library.wmo.int/pmb ged/wmo 1170 en.pdf

[5] Least Developed Countries Expert Group (2012) National Adaptation Plans. Technical Guidelines for the National Adaptation Plan Process. UNFCCC Secretariat, Bonn. http://unfccc.int/NAP

[6] Gerlak, A.K., Guido, Z., Vaughan, C., Rountree, V., Greene, C., Liverman, D., Trotman, A.R., Mahon, R., Cox, S.-A. and Mason, S.J. (2017) Building a Framework for Process-Oriented Evaluation of Regional Climate Outlook Forums. Weather, Climate, and Society, 10, 225-239. https://doi.org/10.1175/WCAS-D-17-0029.1

[7] World Meteorological Organization (2011) The Report of the High-Level Taskforce for the Global Framework for Climate Services, WMO-No. 1065, Publications Board World Meteorological Organization (WMO) 7 bis, Geneva.

[8] Lee, B.-L., Rossi, F., Motha, R. and Stefanski, R. (2013) Implementation Strategy of Global Framework for Climate Service through Global Initiatives in AgroMeteorology for Agriculture and Food Security Sector. Korean Journal of Agricultural and Forest Meteorology, 15, 109-117. https://doi.org/10.5532/KJAFM.2013.15.2.109

[9] Rosas, G., Gubler, S., Oria, C., Acuña, D., Avalos, G., Begert, M., Castillo, E., Croci-Maspoli, M., Cubas, F., Dapozzo, M., Díaz, A., van Geijtenbeek, D., Jacques, M., Konzelmann, T., Lavado, W., Matos, A., Mauchle, F., Rohrer, M., Rossa, A., Scherrer, S.C., Valdez, M., Valverde, M., Villar, G. and Villegas, E. (2016) Towards Implementing Climate Services in Peru-The Project CLIMANDES. Climate Services, 
4, 30-41. https://doi.org/10.1016/j.cliser.2016.10.001

[10] WMO (2014) Annex to the Implementation Plan of the Global Framework for Climate Services-User Interface Platform Component.

[11] Giuliania, G., Nativi, S., Obregon, A., Beniston, M. and Lehmanna, A. (2017) Spatially Enabling the Global Framework for Climate Services: Reviewing Geospatial Solutions to Efficiently Share and Integrate Climate Data \& Information. Climate Services, 8, 44-58. https://doi.org/10.1016/j.cliser.2017.08.003

[12] Swart, R.J., de Bruin, K., Dhenain, S., Dubois, G., Groot, A. and von der Forst, E. (2017) Developing Climate Information Portals with Users: Promises and Pitfalls. Climate Services, 6, 12-22. https://doi.org/10.1016/j.cliser.2017.06.008

[13] Heath-National Adaptation Plan (HNAP) to Climate Change in Tanzania 20182023.

https://www.climatelearningplatform.org/sites/default/files/resources/hnap 26 apri 12018 version for public consultation.pdf

[14] National Framework for Climate Services (2018-2025).

https://www.climatelearningplatform.org/sites/default/files/resources/national fra mework for climate services tanzania final 26 july 2018 0.pdf 